\title{
Preparation of Biowax Esters in Continuous Flow Conditions
}

\author{
Daniela Caputo, ${ }^{\dagger, \ddagger \odot}$ Michele Casiello, ${ }^{\dagger}$ Amelita Grazia Laurenza, ${ }^{\dagger}$ Francesco Fracassi, ${ }^{\dagger}$ \\ Caterina Fusco, ${ }^{\ddagger}$ Angelo Nacci, ${ }^{\dagger, \ddagger(10}$ and Lucia D’Accolti ${ }^{*},, \ddagger$ \\ †Dipartimento di Chimica, Università degli Studi di Bari “A. Moro”, via Orabona 4, 70126 Bari, Italy \\ ${ }^{\ddagger} \mathrm{CNR}$ - Istituto di Chimica dei Composti Organometallici (ICCOM), Bari Section, via Orabona 4, 70126 Bari, Italy
}

Supporting Information

ABSTRACT: Biowaxes synthesized from vegetable fatty acids are an alternative to petrochemical paraffins. A simple way of access to these compounds involves Fisher-type esterification of long-chain acids and alcohols under acidic conditions, but long reaction times and harsh conditions are commonly required. In this study, for the first time in the literature, biowax esters are prepared under flow conditions cutting dramatically both reaction times (from $12 \mathrm{~h}$ to 30 min) and temperature conditions, with respect to batch procedures (from $90-120^{\circ} \mathrm{C}$ to $55^{\circ} \mathrm{C}$ ). This approach brings substantial improvements to the biowax synthesis process from an economic and environmental point of view, thus making the method up-scalable to the industrial level.

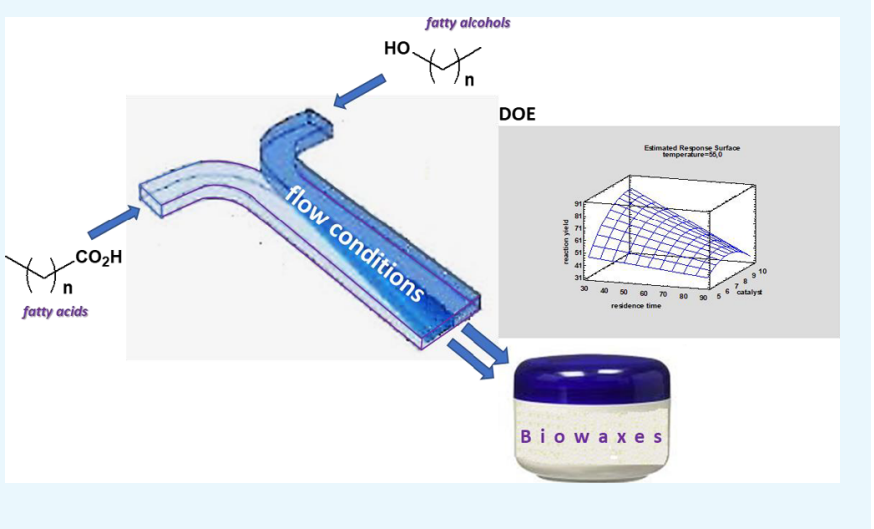

\section{INTRODUCTION}

The term "wax" concerns to naturally solids and amorphous substances at room temperature that become liquid quite easily around $50{ }^{\circ} \mathrm{C}$. The waxes are essentially based on alkanes C20-C30 and represent the $70 \%$ of the market. ${ }^{1}$ These waxes can also be obtained through industrial synthetic processes; for example, polyethylene waxes, which are made by low molecular weight chains $\left(M_{n}\right.$ less than $\left.10,000 \mathrm{Da}\right)$, are prepared by either high-pressure or by Zeigler-type polymerization, ${ }^{2}$ while Fischer-Tropsch wax is produced by carbon monoxide polymerization under high pressure. ${ }^{3}$ Waxes are usually employed as component in lubricants, adhesives, foods, cosmetics, and pharmaceutics. ${ }^{4}$

In recent years, the focus has raised to the study of bio-based waxes obtained essentially from the structural modification of triglycerides of vegetable oils ${ }^{5}$ carried out by partial or full hydrogenation of fatty acid chains or by interesterification to achieve the desired physical properties. ${ }^{4,6}$ Several functional groups are commonly introduced on the acyl chains to improve cohesiveness and tune the wax physicochemical properties, such as hydroxyl or branched alkyl groups and short-chain fatty acids. ${ }^{7,8}$ Another possible approach to prepare biowaxes is the direct esterification of long-chain acids with fatty alcohols ${ }^{4}$ to produce wax esters with chains longer than C30 that are normally harder, less greasy, and more brittle than those obtained by the abovementioned transesterification processes. $^{6,9}$

These waxes are commonly achieved with numerous homogenous catalysts, ${ }^{4,10-12}$ mainly Brønsted acids such as p-toluenesulfonic acid ${ }^{13}$ and $\mathrm{H}_{2} \mathrm{SO}_{4}{ }^{14}$ that are difficult to be removed, thus creating environmental problems such as the large amount of waste generated and reactor corrosion. ${ }^{15,16}$ In addition, other severe limitations such as high temperatures and long reaction times are associated with these processes. Ionic liquid ${ }^{17}$ and enzymes ${ }^{18}$ are also used as catalysts in these direct esterifications.

Likewise, a number of heterogeneous catalysts have been used for wax ester synthesis, for example, Amberlyst-15, ${ }^{6}$ porous meso carbon, ${ }^{16}$ and sulfated zirconia, ${ }^{19}$ getting the undoubted advantages of facile catalyst recovery and reduced waste production, but also in these cases, temperatures over $100{ }^{\circ} \mathrm{C}$ and long reaction times were necessary to achieve satisfactory conversions.

In recent years, flow chemistry has rapidly gained interest due to the numerous improvements introduced in synthetic processes such as automation, safe reproducibility, improved safety, and process reliability. ${ }^{20-22}$ Additionally, reaction parameters settled for laboratory-scale fluidic processes can be used in the up-scaled flow reactors without the need for special optimization procedures. ${ }^{23}$

Several studies concerning the preparation of vegetable oil derivatives under continuous flow conditions have been reported, for example, the epoxidation of soybean oil, ${ }^{24}$ the transesterification to biodiesel, ${ }^{25}$ and the glycerol oligomerization. $^{26}$

In our efforts aimed at developing green synthetic procedures using green catalysts ${ }^{27}$ and natural compounds, ${ }^{28-30}$ we recently reported the application of the

Received: March 28, 2019

Accepted: July 5, 2019

Published: July 17, 2019 
fluidic approach to the oxirane ring opening of epoxidized soybean oil with methanol, ${ }^{31}$ which improved the analogous process conducted in batch in terms of TONs (turnover number), solvent consumption, and reaction times. Following these successful results, we decided to extend the continuous flow strategy to the esterification reaction of fatty acids with long-chain alcohols to prepare biowax esters (Scheme 1).

\section{Scheme 1. Schematic Synthesis of Biowaxes with the} Esterification Reaction

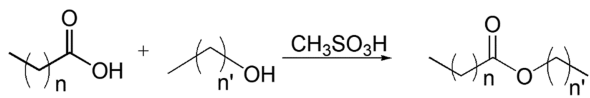

With the goal of obtaining a suitable method for industrial applications, we have developed herein, unprecedented in the literature, the flow chemistry procedure for the esterification of margaric, stearic, oleic, and palmitic acids with an array of alcohols to produce the corresponding ester waxes. $4,6,18,32$ Optimization of reaction conditions has been performed by response surface methodology (RSM).

\section{RESULTS AND DISCUSSION}

Fisher-type esterification of margaric acid (1) with stearyl alcohol (2) to octadecyl heptadecanoate (3) (wax C35) was chosen as the model reaction. This wax ester has received little attention until now, being still prepared with an old procedure, $^{32}$ which starts from acyl chloride and alcohol in the presence of quinoline, thus generating large amounts of byproducts. Direct esterification can be the solution to the waste formation, and flow chemistry can be used to circumvent the problem of low reactivity of the carboxyl group.

Based on a known procedure with an heterogeneous acid catalyst, $^{6}$ a series of preliminary experiments, carried out in a batch mode, enabled us to set the starting conditions to be used in the flow mode statistical optimization (see Experimental Section): acid-alcohol equal to 1.1:1 molar ratio, catalyst loading $\left(\mathrm{CH}_{3} \mathrm{SO}_{3} \mathrm{H}\right) 5 \%$ (w/w with respect to acid), temperature of $95{ }^{\circ} \mathrm{C}$, and reaction time of $12 \mathrm{~h}$. The wax (3) product showed the identical physicochemical features as those described in the literature. ${ }^{32}$

Optimization of Esterification Parameters with the DOE Method. The three reaction factors (temperature, residence time, and wt \% of catalyst) were optimized by means of 15 experiments as statistically required by the BoxBehnken design (Table 1). Based on instrumental limits and literature evidences, ${ }^{4,6}$ the ranges of $55-95^{\circ} \mathrm{C}$ (for $\mathrm{T}$ ), 30-90 $\min$ (for RT), and 5-10\% (for wt \% of catalyst) were chosen for applying the DOE method.

Based on literature evidences, $\mathrm{CHCl}_{3}$ was used as the solvent. ${ }^{4,10,12}$ In addition, the acid-alcohol ratio was excluded from the statistical treatment. Indeed, this factor has been already explored in reactions conducted in batch, ${ }^{4}$ with ratios ranging from equimolar amounts, for example, used with sulfonic-based heterogeneous catalysts (Amberlyst), ${ }^{6}$ to large excesses of carboxylic acid (5.10:1). ${ }^{14}$ Being the conditions adopted in this work, more similar to the former case, with methane sulfonic acid used as the catalyst, a quite similar acidalcohol molar ratio (1.1:1) was chosen for carrying the DOE method.

Statistical Analysis of Experimental Design. Table 2 reports the analysis by the ANOVA method of the experiments
Table 1. Application of the DOE Method to the Synthesis of Biowax (3): Parameter Optimization ${ }^{a}$

\begin{tabular}{|c|c|c|c|c|}
\hline run & $\begin{array}{l}\text { temperature } \\
\left({ }^{\circ} \mathrm{C}\right)\end{array}$ & residence time $(\mathrm{min})$ & catalyst (wt \%) & yield (\%) \\
\hline 1 & 95 & 30 & 7.5 & 77 \\
\hline 2 & 75 & 60 & 7.5 & 65 \\
\hline 3 & 75 & 90 & 10 & 31 \\
\hline 4 & 75 & 30 & 10 & 80 \\
\hline 5 & 75 & 90 & 5 & 42 \\
\hline 6 & 55 & 60 & 5 & 41 \\
\hline 7 & 95 & 60 & 5 & 36 \\
\hline 8 & 55 & 30 & 7.5 & 69 \\
\hline 9 & 95 & 90 & 7.5 & 51 \\
\hline 10 & 75 & 60 & 7.5 & 64 \\
\hline 11 & 55 & 60 & 10 & 61 \\
\hline 12 & 95 & 60 & 10 & 63 \\
\hline 13 & 75 & 30 & 5 & 52 \\
\hline 14 & 75 & 60 & 7.5 & 66 \\
\hline 15 & 55 & 90 & 7.5 & 39 \\
\hline
\end{tabular}

${ }^{a}$ Reaction conditions as reported in Experimental Section.

Table 2. Analysis of Variance for Reaction Yields

\begin{tabular}{lccc}
\multicolumn{1}{c}{ source } & Df $^{a}$ & mean square & $P$-value \\
temperature $^{a}$ & 1 & 36.125 & 0.3646 \\
residence time $^{a}$ & $\mathbf{1}$ & $\mathbf{1 6 5 3 . 1 3}$ & $\mathbf{0 . 0 0 1 1}$ \\
catalyst $^{a}$ & $\mathbf{1}$ & $\mathbf{5 1 2 . 0}$ & $\mathbf{0 . 0 1 3 3}$ \\
$\mathrm{AA}$ & 1 & 45.2308 & 0.3154 \\
$\mathrm{AB}$ & 1 & 4.0 & 0.7536 \\
$\mathrm{AC}$ & 1 & 12.25 & 0.5867 \\
$\mathrm{BB}$ & 1 & 23.0769 & 0.4617 \\
$\mathrm{BC}$ & $\mathbf{1}$ & $\mathbf{3 8 0 . 2 5}$ & $\mathbf{0 . 0 2 3 1}$ \\
$\mathrm{CC}$ & $\mathbf{1}$ & $\mathbf{4 6 7 . 3 0 8}$ & $\mathbf{0 . 0 1 5 8}$ \\
total error & 5 & 36.35 & \\
total (corr.) & 14 & & \\
\hline
\end{tabular}

${ }^{a} \mathrm{~A}$, temperature; B, residence time; C, catalyst; Df, degrees of freedom.

described in Table 1 to evaluate the "grade of fitting". From statistical parameters obtained, it clearly emerged that parameters B, C, BC, and CC (reported in bold) are statistically significant at a confidence level of $95 \%$ (since they have a $P$-value less than 0.05). Therefore, the ANOVA table shows that the significant variables affecting the response are the residence time, amount of catalyst, and their interaction.

Due to the high $P$-values (greater than 0.05 ), parameters such as temperature, interaction temperature-residence time, interaction temperature-catalyst, and quadratic terms of temperature and residence time were not found to be significant.

The effects of each factor can be visualized graphically in Figure 1 where the reaction time clearly emerged as a crucial parameter that affected dramatically reaction yields, showing a highly negative slope. Indeed, when the time was prolonged to 90 min, yield of 3 dropped drastically to $31 \%$ (run 3, Table 1), thus indicating that for long time reverse reaction of hydrolysis becomes predominant, similarly to what reported in the literature for the synthesis of methyl laurate. ${ }^{33}$ 
Main Effects Plot for reaction yield

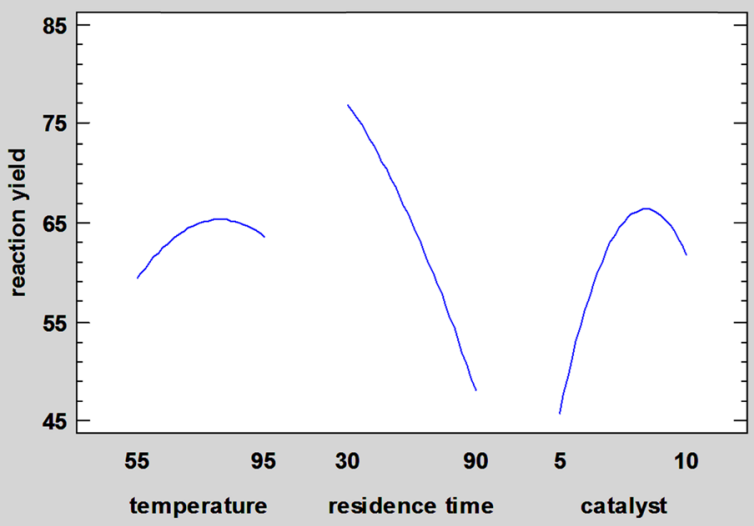

Figure 1. Main effect plots for reaction yield.

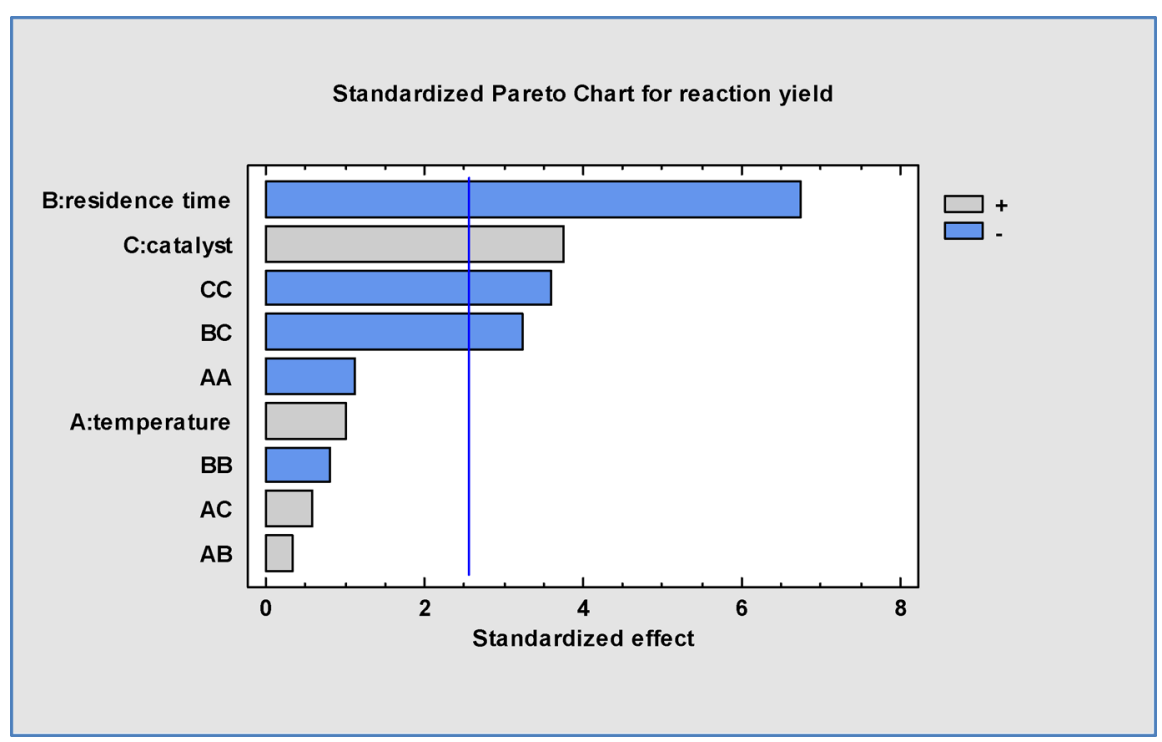

Figure 2. Standardized Pareto chart.

Two control experiments were carried out to ascertain this assumption, conducting reactions under optimized conditions of temperature $\left(55^{\circ} \mathrm{C}\right)$ and wt $\%$ of catalyst $(9.54 \%)$ and monitoring conversions at 60 and $90 \mathrm{~min}$.

As expected, the starting stearyl alcohol increased with prolonged times while simultaneously decreased the wax C35 (3) yield. A different mode way of depicting the influence of the three variables studied and their mutual influence was given by the Pareto chart (Figure 2).

Using Statgraphics Centurion XVII software, a quadratic model was found to be appropriate for accounting experimental results in agreement with the following equation $\left(R^{2}=0.944595\right)$ :

$$
\begin{aligned}
\text { yield }= & -89.5714+0.495833 \mathrm{RT}+36.9714 \% \text { wt cat. } \\
& -0.13 \mathrm{RT}^{\circ}{ }^{\circ} \% \text { of catalyst }-1.73143 \% \text { wt cat. }
\end{aligned}
$$

The software also provided the response surface graph according to the quadratic model, together with the optimized parameters (Figure 3).
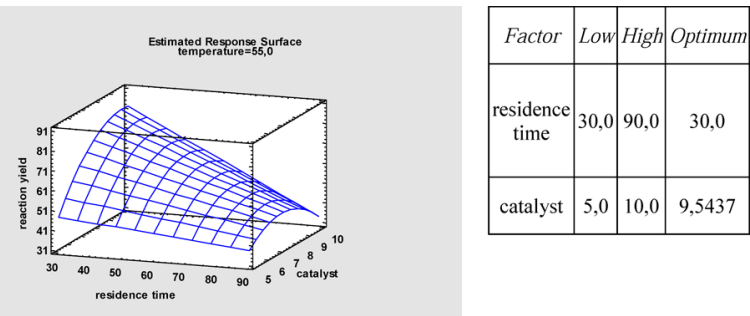

Figure 3. Response surface graph and optimized parameters.

As the temperature did not have a significant effect in the range studied, for the successive experiments, the lowest value of $55{ }^{\circ} \mathrm{C}$ was employed. To validate results obtained with the DOE method, a control experiment was performed using the optimized parameters of temperature, $55^{\circ} \mathrm{C}$; residence time, $30 \mathrm{~min}$; and wt \% of catalyst, $9.54 \%$. Reaction yield obtained under these conditions was $80 \pm 1 \%$. On the other hand, when 
Table 3. Substrate Scope ${ }^{a}$

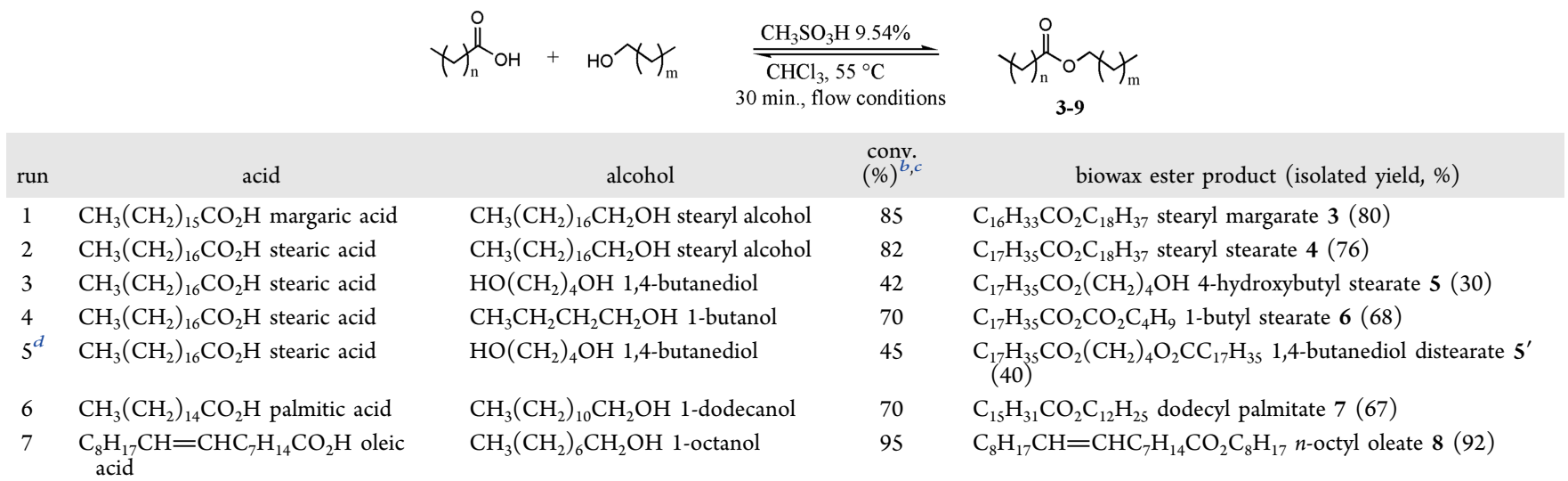

${ }^{a}$ Reaction conditions: acid-alcohol $(1.1: 1 \mathrm{~mol})$, catalyst $\left(\mathrm{CH}_{3} \mathrm{SO}_{3} \mathrm{H}\right) 9.54 \%$ (wt), solvent $\mathrm{CHCl}_{3}, \mathrm{~T}=55{ }^{\circ} \mathrm{C}$, residence time $(30$ min). ${ }^{b}$ Conversion evaluated by GC-MS. ${ }^{c}$ Selectivity was found to be $100 \%$ in each ester product. ${ }^{d}$ Acid-alcohol = $2: 1$ molar ratio.

these conditions were applied in a batch mode, a yield of $17 \pm$ $1 \%$ was obtained.

Substrate Scope. After achieving the optimal reaction conditions, a substrate scope was conducted for preparing, for the first time under flow conditions, biowax esters $\mathbf{3} \mathbf{- 8}$ coming from margaric, oleic, palmitic, and stearic acids and an array of alcohols.

Results in Table 3 show from good to excellent yields in the range of $67-92 \%$, with the sole exception of 4-hydroxybutyl stearate 5 (run 3), which was obtained in modest yield probably due to the higher polarity of the starting diol.

To verify this latter hypothesis, 1,4-butanediol was replaced with the less polar monoalcohol having the same alkyl chain 1butanol, thus obtaining the corresponding $n$-butyl stearate (6) with a $68 \%$ of isolated yield, demonstrating that the high polarity of starting materials represents a limit for this protocol (run 4).

Further evidences on the influence of polarity came from the reaction of diol with excess amounts of stearic acid where the exclusive formation of diester $\mathbf{5}^{\prime}$ was detected, again in modest yield (40\%), but without any trace of monoester 5 (run 5). In this case, monoester 5 intermediate, once formed, competes favorably with the less soluble butanediol for carboxylic acid, thus shifting reaction completely toward the formation of diester.

Both stearyl stearate (4) and 4-hydroxybutyl stearate (5) (Table 3, runs 1 and 2) are useful waxes employed for producing corrugated coatings. ${ }^{6}$

They are prepared in higher yields in a batch mode but require very long reaction times and higher temperatures, thus rendering a less sustainable esterification process. ${ }^{6,11,34-37}$

Dodecyl palmitate (7) and $n$-octyl oleate (8), suitable compounds for the formulation of cosmetics, ${ }^{18}$ were obtained in high yields under flow conditions (Table 3, runs 4 and5), thus making this method more convenient than the previously reported processes based on biocatalysts (lipase), ${ }^{38,39} \mathrm{scCO} 2$ as the reaction medium, ${ }^{40}$ and organocatalysts supported on $\mathrm{N}$-doped graphene oxide. ${ }^{41}$ Most of these latter procedures are not useful for industrial applications because of the high cost of catalysts or the hard experimental condition requirements.

\section{CONCLUSIONS}

In conclusion, the replacement of the batch process with continuous flow synthesis in the preparation of wax esters from long-chain alcohols and fatty acids resulted in a remarkable process improvement. Compared with the batch reaction, the flow mode enabled (i) to cut the reaction time from $12 \mathrm{~h}$ to 30 min, (ii) to lower temperature $\left(55{ }^{\circ} \mathrm{C}\right)$ with respect to literature procedures $\left(90-120{ }^{\circ} \mathrm{C}\right.$ ), and (iii) to reduce quantities of solvent (half amounts with respect to the batch mode). All these milder conditions brought significant benefits in terms of energy consumption, cost efficiency, and ecosustainability. Notably, when flow conditions were applied to the batch mode synthesis of waxes $3-7$, reaction yields did not exceed $20 \%$.

All these benefits indicate that this new procedure of biowax ester synthesis, which has no precedent in the literature, has a good potential for industrial applications.

\section{EXPERIMENTAL SECTION}

Materials and Methods. A Vapourtec R-series flow reactor was used in the synthesis of biowaxes. The reactor consists of a $10 \mathrm{~mL}$ PFA tube, inserted inside a quartz enclosure and wrapped in spire, for temperature monitoring. The "reagent in" port of the reactor coil was connected to the pump with a length of PFA tubing. The "reagent out" port was then directly interfaced with an 8 bar back pressure regulator after which there is a PFA tube connected to a collection vial. The instrument has several digital control displays for physical parameters, such as the residence time (flow rate) and temperature.

In particular, the residence time can be varied from 2 to 200 min, while the temperature can be controlled in the range of room temperature to $150{ }^{\circ} \mathrm{C}$.

NMR spectra were recorded on an Agilent Technologies $500 \mathrm{MHz}$ spectrometer; the ${ }^{1} \mathrm{H}$ resonance signals were referenced to residual isotopic impurity of $\mathrm{CDCl}_{3}$ (7.26 $\mathrm{ppm})$. The ${ }^{13} \mathrm{C}$ resonance signals were referenced to residual isotopic impurity of $\mathrm{CDCl}_{3}(77.00 \mathrm{ppm})$. GC-MS experiments were run on a Shimadzu GLC 17-A instrument connected with a Shimadzu QP5050A selective mass detector using an SLB-5MS column $(30 \mathrm{~m} \times 0.25 \mathrm{~mm}$ i.d.; film thickness, $0.25 \mu \mathrm{m})$. Mass spectra were performed in an EI mode $(70 \mathrm{eV})$. High-resolution mass spectra (HRMS) were obtained using a Shimadzu LCMS-IT-TOF instrument with the following settings: mass range $50-1000 \mathrm{~m} / z$, ionization system electrospray ion source in the positive ion mode, 
nebulizer gas nitrogen at $1.5 \mathrm{~L} / \mathrm{min}$, dry gas nitrogen at 1.2 $\mathrm{MPa}$, and collision gas argon at $250{ }^{\circ} \mathrm{C}$.

General Batch Mode Synthesis of Wax C35 Octadecyl Heptadecanoate (3). Preparation of 3 was performed according to an analogous procedure for the synthesis of wax esters: ${ }^{6}$ in a $25 \mathrm{~mL}$ round-bottom flask equipped with a condenser, $110 \mathrm{mg}$ of margaric acid $(0.407 \mathrm{mmol}), 100 \mathrm{mg}$ of stearyl alcohol $(0.369 \mathrm{mmol})$, and $3.72 \mu \mathrm{L}$ of methanesulfonic acid as the catalyst $(d=1.48 \mathrm{~g} / \mathrm{mL} ; 0.057 \mathrm{mmol})$ were dissolved in $5 \mathrm{~mL}$ of chloroform and heated under stirring at $95{ }^{\circ} \mathrm{C}$ for $12 \mathrm{~h}$. The reaction progress was monitored by GCMS analysis. Next, the reaction mixture was washed consecutively with aqueous solutions of $\mathrm{Na}_{2} \mathrm{CO}_{3}$ and $\mathrm{NaHCO}_{3}$ to remove the excess of heptadecanoic acid and the catalyst and finally washed with deionized water until neutrality. Then, the organic phase was dried, and the solvent $\mathrm{CHCl}_{3}$ was evaporated under vacuum. The crude ester was recrystallized from ethanol affording $68 \mathrm{mg}(70 \%)$ of octadecyl heptadecanoate (3) in high purity (mp 60-63 ${ }^{\circ} \mathrm{C}$, lit. 61.1 $\left.{ }^{\circ} \mathrm{C}^{32}\right) .{ }^{1} \mathrm{H} \mathrm{NMR}\left(\mathrm{CDCl}_{3}, 500 \mathrm{MHz}\right): \delta 4.05(\mathrm{t}, J=6.5 \mathrm{~Hz}$, $2 \mathrm{H}), 2.28(\mathrm{t}, J=7.5,2 \mathrm{H}), 1.61$ (broad $\mathrm{m}, 2 \mathrm{H}), 1.25(\mathrm{~m}, 58 \mathrm{H})$, $0.88(\mathrm{t}, J=7.0,6 \mathrm{H}) \cdot{ }^{13} \mathrm{C} \mathrm{NMR}\left(\mathrm{CDCl}_{3}, 125 \mathrm{MHz}\right): \delta 174.0$, 64.4, 34.4, 31.9, 30.9, 29.7, 29.6, 29.5, 29.4, 29.3, 29.1, 28.6, 25.9, 25.0, 22.7, 14.1. GC-MS (EI) $(70 \mathrm{eV}) \mathrm{m} / z$ (\%): 522 $\left(\mathrm{M}^{+}, 29\right), 271$ (100), 57 (43) 43 (40). HRMS (ESI-TOF) $\mathrm{m} / z$ $[\mathrm{M}+\mathrm{Na}]^{+}$: calcd for $\mathrm{C}_{35} \mathrm{H}_{70} \mathrm{NaO}_{2}{ }^{+}$: 545.5284; found, 545.5224

General Procedure for the Synthesis of Wax C35 (3) in Flow Conditions. Two milliliters of a chloroform solution of margaric acid $(14.8 \mathrm{mg}, 0.054 \mathrm{mmol})$ was injected in the loop A (Scheme 2), and $2 \mathrm{~mL}$ of a chloroform solution of

Scheme 2. Representative Scheme of the Continuous Flow Reactor

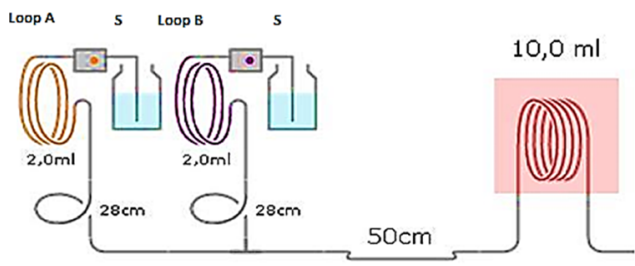

Reactor

stearyl alcohol (13.4 mg, $0.049 \mathrm{mmol}$ ) and methanesulfonic acid $(1.0 \mu \mathrm{L}, 10 \mathrm{wt} \%)$ were injected in the loop B. Both bottles were labeled as $S$ contained chloroform, which is the solvent of the reaction. Two pumps were charged using the start-up sequence suggested from the equipment manufacturer. Initially, chloroform was pumped inside the reactor heated to $55{ }^{\circ} \mathrm{C}$ at a flow rate of $0.5 \mathrm{~mL} / \mathrm{min}$. Then, by means of switches on the unit, both the reagent in loop A and loop B were flowed simultaneously at a flow rate of $0.334 \mathrm{~mL} / \mathrm{min}$, which corresponds to a calculated residence time of $30 \mathrm{~min}$. When the reagents had been processed from the loops, the flow was switched back from loops to solvent, and the reaction product, obtained at the exit of the reactor coil, was extracted with the same procedure adopted in the batch mode.

Experimental Design and Data Analysis. The three specific reaction parameters "temperature, residence time, and wt \% of catalyst" were studied through the experimental optimization design (DOE) method, applying the BoxBehnken design elaborated by Statgraphics Centurion XVII software. Fifteen experiments were carried out in order to study the effects of three factors (reported in Table 1). The runs were conducted in a single block, and the order of the experiments was completely randomized to eliminate the effects of latent variables. DOE allows evaluating the influence of the temperature, residence time, and amount of catalyst and any interaction between the factors, according to a quadratic polynomial model with a general formula

$$
\begin{aligned}
Y= & \beta_{0}+\beta_{1} x_{1}+\beta_{2} x_{2}+\beta_{3} x_{3}+\beta_{12} x_{1} x_{2}+\beta_{23} x_{2} x_{3} \\
& +\beta_{13} x_{1} x_{3}+\beta_{11} x_{1}^{2}+\beta_{22} x_{2}^{2}+\beta_{33} x_{3}^{2}
\end{aligned}
$$

where $x_{1}, x_{2}$, and $x_{3}$ are the experimental variables $(T, \mathrm{RT}$, and wt $\%$ of catalyst, respectively), while $\beta_{0}, \beta_{1}, \beta_{2}, \beta_{3}, \beta_{12}, \beta_{23}, \beta_{13}$, $\beta_{11}, \beta_{22}$, and $\beta_{33}$ are the coefficients of the polynomial model, and $Y$ is the response (reaction yield).

Synthesis and Characterization of Biowax Esters (48) in Flow Conditions. The optimized flow conditions for wax (3) were applied to the preparation of biowax esters (48). All the products, except for (7), which is an oil, ${ }^{42}$ are white solids. Stearyl stearate (4) $\left(\mathrm{mp} 58-60{ }^{\circ} \mathrm{C}\right.$, lit. $\left.59{ }^{\circ} \mathrm{C}^{35}\right) ;{ }^{1} \mathrm{H}$ $\mathrm{NMR},{ }^{13} \mathrm{C} \mathrm{NMR}$, and IR spectra were in agreement with the literature. $^{11,34,36} \mathrm{GC}-\mathrm{MS}$ analysis (EI) $(70 \mathrm{eV}) \mathrm{m} / z(\%): 536$ $\left(\mathrm{M}^{+}, 10\right), 285$ (70), 57 (100), 43 (71). HRMS (ESI-TOF) $\mathrm{m} /$ $z[\mathrm{M}+\mathrm{Na}]^{+}$: calcd for $\mathrm{C}_{36} \mathrm{H}_{72} \mathrm{NaO}_{2}{ }^{+}, 559.5425$; found, 559.5399. 4-Hydrossibutyl stearate (5) (mp $42{ }^{\circ} \mathrm{C}$, lit. $40.5-$ $\left.41{ }^{\circ} \mathrm{C}^{37}\right) ;{ }^{1} \mathrm{H} \mathrm{NMR},{ }^{13} \mathrm{C} \mathrm{NMR}$, and IR spectra were in agreement with the literature. ${ }^{6} \mathrm{GC}-\mathrm{MS}$ analysis (EI) $(70 \mathrm{eV})$ $m / z(\%): 356\left(\mathrm{M}^{+}, 8\right), 285$ (12), 73 (100), 43 (48). HRMS (ESI-TOF) $m / z[\mathrm{M}+\mathrm{Na}]^{+}$: calcd for $\mathrm{C}_{22} \mathrm{H}_{44} \mathrm{NaO}_{3}{ }^{+}$, 379.3183; found, 379.3128 .

1,4-Butanediol distearate $\left(5^{\prime}\right)\left(\mathrm{mp} 59{ }^{\circ} \mathrm{C}\right.$, lit. $\left.60-62{ }^{\circ} \mathrm{C}^{43}\right)$; ${ }^{1} \mathrm{H}$ NMR and ${ }^{13} \mathrm{C}$ NMR spectra were in agreement with the literature. ${ }^{44} \mathrm{GC}-\mathrm{MS}$ analysis (EI) $(70 \mathrm{eV}) \mathrm{m} / z(\%): 622\left(\mathrm{M}^{+}\right.$, 5), 339 (29), 267 (24), 73 (100). HRMS (ESI-TOF) $m / z[M$ $+\mathrm{Na}]^{+}$: calcd for $\mathrm{C}_{40} \mathrm{H}_{78} \mathrm{NaO}_{4}{ }^{+}, 645.5798$; found, 645.5901.

1-Butyl stearate (6) (mp 41-44 ${ }^{\circ} \mathrm{C}$, lit. $\left.43-44{ }^{\circ} \mathrm{C}^{45}\right) ;{ }^{1} \mathrm{H}$ $\mathrm{NMR},{ }^{13} \mathrm{C}$ NMR, and IR spectra were in agreement with the literature. ${ }^{45} \mathrm{GC}-\mathrm{MS}$ analysis (EI) $(70 \mathrm{eV}) \mathrm{m} / z(\%): 340\left(\mathrm{M}^{+}\right.$, 12), 285 (24), 267 (17), 56 (100). HRMS (ESI-TOF) $\mathrm{m} / z[\mathrm{M}$ $+\mathrm{Na}]^{+}$: calcd for $\mathrm{C}_{22} \mathrm{H}_{44} \mathrm{NaO}_{2}{ }^{+}, 363.3239$; found, 363.3244 .

Dodecyl palmitate (7) (mp $39.5{ }^{\circ} \mathrm{C}$, lit. $\left.39.4{ }^{\circ} \mathrm{C}^{32}\right) ;{ }^{1} \mathrm{H}$ $\mathrm{NMR},{ }^{13} \mathrm{C} \mathrm{NMR}$, and IR spectra were in agreement with the literature. ${ }^{9,38,46} \mathrm{GC}-\mathrm{MS}$ analysis (EI) $(70 \mathrm{eV}) \mathrm{m} / z(\%): 424$ $\left(\mathrm{M}^{+}, 10\right), 257$ (70), 57 (100), 43 (83). HRMS (ESI-TOF) $\mathrm{m} /$ $z[\mathrm{M}+\mathrm{Na}]^{+}$: calcd for $\mathrm{C}_{28} \mathrm{H}_{56} \mathrm{NaO}_{2}{ }^{+}, 447.4173$; found, 447.4155. Octyl cis-9-octadecenoate (8); ${ }^{1} \mathrm{H} \mathrm{NMR},{ }^{13} \mathrm{C} \mathrm{NMR}$, and IR spectra were in agreement with the literature. ${ }^{17,19} \mathrm{GC}-$ MS analysis (EI) $(70 \mathrm{eV}) \mathrm{m} / z(\%): 394\left(\mathrm{M}^{+}, 5\right), 264$ (22), 69 (93), 57 (100). HRMS (ESI-TOF) $m / z[\mathrm{M}+\mathrm{K}]^{+}$: calcd for $\mathrm{C}_{26} \mathrm{H}_{50} \mathrm{KO}_{2}^{+}$, 433.3442; found, 433.3544 .

\section{ASSOCIATED CONTENT}

\section{S Supporting Information}

The Supporting Information is available free of charge on the ACS Publications website at DOI: 10.1021/acsomega.9b00861.

Characterization ${ }^{1} \mathrm{H}$ NMR, ${ }^{13} \mathrm{C}$ NMR, and HRMS spectra for compounds $\mathbf{3}-\mathbf{8}$ (PDF)

\section{AUTHOR INFORMATION}

\section{Corresponding Author}

*E-mail: lucia.daccolti@uniba.it. 


\section{ORCID $\odot$}

Daniela Caputo: 0000-0001-8860-9141

Michele Casiello: 0000-0002-0836-9318

Caterina Fusco: 0000-0001-9862-0248

Angelo Nacci: 0000-0002-8271-0692

Lucia D’Accolti: 0000-0002-4960-728X

\section{Author Contributions}

The manuscript was written through contributions of all authors. All authors have given approval to the final version of the manuscript.

\section{Notes}

The authors declare no competing financial interest.

\section{ACKNOWLEDGMENTS}

All the authors received funding from the European UnionFESR "PON Ricerca e Innovazione 2014-2020. Progetto: Energie per l'Ambiente TARANTO-Cod. ARS01_00637”.

\section{REFERENCES}

(1) Krendlinger, E.; Wolfmeier, U.; Schmidt, H.; Heinrichs, F.-L.; Michalczyk, G.; Payer, W.; Dietsche, W.; Boehlke, K.; Hohner, G.; Wildgruber, J. Ullmann's Waxes in Encyclopedia of Industrial Chemistry; Wiley-VCH Verlag GmbH \& Co. KGaA, 2015; pp 111-172.

(2) Brandrup, J., Immergut, E. H., Grulke, E. A. Polymer handbook 4th edition; A Wiley Intersnence Publication: US, 1999, pp. 15031508 .

(3) Fazaeli, H.; Amini, A. A.; Nejad, F. M.; Behbahani, H. Rheological properties of bitumen modified with a combination of FT paraffin wax (sasobit $\left.{ }^{\circledR}\right)$ and other additives. J. Civ. Eng. Manage. 2016, 22, 135-145.

(4) Fei, T.; Wang, T. A review of recent development of sustainable waxes derived from vegetable oils. Curr. Opin. Food Sci. 2017, 16, 714.

(5) Oliver-Tomas, B.; Renz, M.; Corma, A. High Quality Biowaxes from Fatty Acids and Fatty Esters: Catalyst and Reaction Mechanism for Accompanying Reactions. Ind. Eng. Chem. Res. 2017, 56, 1287012877.

(6) Fei, T.; Walker, J. A.; Vickerman, K. L.; Stanley, L. M.; Jarboe, D.; Wang, T. Synthesis and characterization of soybean oil-based waxes and their application as paraffin substitute for corrugated coating. J. Ind. Eng. Chem. 2018, 58, 113-122.

(7) Feuge, R. O.; Vicknair, E. J.; Lovegren, N. V. Modification of Vegetable Oils. XII. Plasticity of Some Aceto Derivatives of Monostearin. J. Am. Oil Chem. Soc. 1952, 29, 11-14.

(8) Pelloso, T. A.; Roden, A. D.; Boldt, G. L. Synthesis of Acetoglyceride FATS. US Patent PN US5,434,278A 1995.

(9) Syamsul, K. M. W.; Salina, M. R.; Siti, S. O.; Hanina, M. N.; Basyaruddin, M. A. R.; Jusoff, K. Green Synthesis of Lauryl Palmitate via Lipase-Catalyzed Reaction. World Appl. Sci. J. 2010, 11, 401-407.

(10) Bouzidi, L.; Li, S.; Di Biase, S.; Rizvi, S. Q.; Narine, S. S. Lubricating and waxy esters, I. Synthesis, crystallization, and melt behavior of linear monoesters. Chem. Phys. Lipids 2012, 165, 38-50.

(11) Reddy, N. N. K.; Ravi, C.; Adimurthy, S. Oxidative esterification of primary alcohols at room temperature under aqueous medium. Synth. Commun. 2018, 48, 1663-1670.

(12) Kleinová, A.; Fodran, P.; Brnčalová, L.; Cvengroš, J. Substituted esters of stearic acid as potential lubricants. Biomass Bioenergy 2008, 32, 366-371.

(13) De Santi, V.; Cardellini, F.; Brinchi, L.; Germani, R. Novel Brønsted acidic deep eutectic solvent as reaction media for esterification of carboxylic acid with alcohols. Tetrahedron Lett. 2012, 53, 5151-5155.

(14) Beula, C.; Sai, P. S. T. Kinetics of Esterification of Palmitic acid with Ethanol-Optimization Using Statistical Design of Experiments. Int. J. Chem. Eng. Appl. 2013, 4, 388-392.
(15) Ramu, S.; Lingaiah, N.; Prabhavathi Devi, B. L. A.; Prasad, R. B. N.; Suryanarayana, I.; Sai Prasad, P. S. Esterification of palmitic acid with methanol over tungsten oxide supported on zirconia solid acid catalysts: effect of method of preparation of the catalyst on its structural stability and reactivity. Appl. Catal., A 2004, 276, 163-168.

(16) Geng, L.; Wang, Y.; Yu, G.; Zhu, Y. Efficient carbon-based solid acid catalysts for the esterification of oleic acid. Catal. Commun. 2011, $13,26-30$.

(17) Porwal, J.; Kumar, S.; Kaul, S.; Jain, S. L. Guanidine based task specific ionic liquids for the synthesis of biolubricant range esters under solvent-free condition. RSC Adv. 2016, 6, 93640-93644.

(18) Khan, N. R.; Rathod, V. K. Enzyme catalyzed synthesis of cosmetic esters and its intensification: A review. Process Biochem. 2015, 50, 1793-1806.

(19) Oh, J.; Yang, S.; Kim, C.; Choi, I.; Kim, J. H.; Lee, H. Synthesis of biolubricants using sulfated zirconia catalysts. Appl. Catal., A 2013, $455,164-171$.

(20) Hartman, R. L.; McMullen, J. P.; Jensen, K. F. Deciding Whether To Go with the Flow: Evaluating the Merits of Flow Reactors for Synthesis. Angew. Chem. Int. Ed. 2011, 50, 7502-7519.

(21) Pirotte, G.; Kesters, J.; Verstappen, P.; Govaerts, S.; Manca, J.; Lutsen, L.; Vanderzande, D.; Maes, W. Continuous Flow Polymer Synthesis toward Reproducible Large-Scale Production for Efficient Bulk Heterojunction Organic Solar Cells. ChemSusChem 2015, 8, $3228-3233$.

(22) Helgesen, M.; Carlé, J. E.; dos Reis Benatto, G. A.; Søndergaard, R. R.; Jørgensen, M.; Bundgaard, E.; Krebs, F. C. Making Ends Meet: Flow Synthesis as the Answer to Reproducible High-Performance Conjugated Polymers on the Scale that Roll-toRoll Processing Demands. Adv. Energy Mater. 2015, 1401996.

(23) Wegner, J.; Ceylan, S.; Kirschning, A. Ten key issues in modern flow chemistry. Chem. Commun. 2011, 47, 4583-4592.

(24) He, W.; Fang, Z.; Ji, D.; Chen, K.; Wan, Z.; Li, X.; Gan, H.; Tang, S.; Zhang, K.; Guo, K. Epoxidation of Soybean Oil by Continuous Micro-Flow System with Continuous Separation. Org. Process Res. Dev. 2013, 17, 1137-1141.

(25) Tran, D.-T.; Chang, J.-S.; Lee, D.-J. Recent insights into continuous-flow biodiesel production via catalytic and non-catalytic transesterification processes. Appl. Energy 2017, 185, 376-409.

(26) Galy, N.; Nguyen, R.; Blach, P.; Sambou, S.; Luart, D.; Len, C. Glycerol oligomerization in continuous flow reactor. J. Ind. Eng. Chem. 2017, 51, 312-318.

(27) Iannone, F.; Casiello, M.; Monopoli, A.; Cotugno, P.; Sportelli, M. C.; Picca, R. A.; Cioffi, N.; Dell'Anna, M. M.; Nacci, A. Ionic liquids/ $\mathrm{ZnO}$ nanoparticles as recyclable catalyst for polycarbonate depolymerization. J. Mol. Catal. A: Chem. 2017, 426, 107-116.

(28) Annese, C.; Abbrescia, D. I.; Catucci, L.; D’Accolti, L.; Denora, N.; Fanizza, I.; Fusco, C.; La Piana, G. Site-dependent Biological Activity of Valinomycin Analogs Bearing Derivatizable Hydroxyl Sites. J. Pept. Sci. 2013, 19, 751-757.

(29) D’Accolti, L.; Annese, C.; Fusco, C. Direct Regio- and Stereoselective Synthesis of Squalene 2,3;22,23-Dioxide using Dioxiranes. Tetrahedron Lett. 2005, 46, 8459-8462.

(30) Sekimata, K.; Hatano, K.; Ogawa, M.; Abe, J.; Magata, Y.; Biggio, G.; Serra, M.; Laquintana, V.; Denora, N.; Latrofa, A.; Trapani, G.; Liso, G.; Ito, K Radiosynthesis and in vivo evaluation of $\mathrm{N}$-[11C]methylated imidazopyridineacetamides as PET tracers for peripheral benzodiazepine receptors. Nucl. Med. Biol. 2008, 35, 327334.

(31) Pantone, V.; Laurenza, A. G.; Annese, C.; Fracassi, F.; Fusco, C.; Nacci, A.; Russo, A.; D’Accolti, L. Methanolysis of epoxidized soybean oil in continuous flow conditions. Ind. Crops Prod. 2017, 109, $1-7$.

(32) Kreger, D. R.; Schamhart, C. On the Long crystal-spacings In Wax Esters And Their Value In Micro-Analysis of Plant Cuticle Waxes. Biochim. Biophys. Acta 1956, 19, 22-44.

(33) Han, B.; Yin, F.; Liu, S.; Zhao, X.; Liu, J.; Wang, C.; Yang, H.; Zhang, W. Synthesis and Optimization of Methyl Laurate Using 
Sulfonated Pyrrolidonium Ionic Liquid as a Catalyst. Int. J. Chem. React. Eng. 2019, 17, 1542.

(34) Touchy, A. S.; Kon, K.; Onodera, W.; Shimizu, K.-i. Unprecedented Reductive Esterification of Carboxylic Acids under Hydrogen by Reusable Heterogeneous Platinum Catalysts. Adv. Synth. Catal. 2015, 357, 1499-1506.

(35) Seethamraju, S.; Ramamurthy, P. C.; Madras, G. Organic passivation layer on flexible Surlyn substrate for encapsulating organic photovoltaics. Appl. Phys. Lett. 2014, 105, 104102-1041104.

(36) Chakraborti, A. K.; Singh, B.; Chankeshwara, S. V.; Patel, A. R. Protic Acid Immobilized on Solid Support as an Extremely Efficient Recyclable Catalyst System for a Direct and Atom Economical Esterification of Carboxylic Acids with Alcohols. J. Org. Chem. 2009, 74, 5967-5974.

(37) Iwashita, M.; Makide, K.; Nonomura, T.; Misumi, Y.; Otani, Y.; Ishida, M.; Taguchi, R.; Tsujimoto, M.; Aoki, J.; Arai, H.; Ohwada, T. Synthesis and Evaluation of Lysophosphatidylserine Analogues as Inducers of Mast Cell Degranulation. Potent Activities of Lysophosphatidylthreonine and Its 2-Deoxy Derivative. J. Med. Chem. 2009, 52, 5837-5863.

(38) Louw, S.; Burger, B. V.; le Roux, M.; van Wyk, J. H. Lizard Epidermal Gland Secretions. II. Chemical Characterization of the Generation Gland Secretion of the Sungazer, Cordylus giganteus. J. Nat. Prod. 2011, 74, 1364-1369.

(39) Seo, C. W.; Yamada, Y.; Okada, H. Synthesis of Fatty Acid Esters by Corynebacteriumsp. S-401. Agric. Biol. Chem. 2014, 46, 405-409.

(40) Laudani, C. G.; Habulin, M.; Knez, Ž.; Della Porta, G.; Reverchon, E. Lipase-catalyzed long chain fatty ester synthesis in dense carbon dioxide: Kinetics and thermodynamics. J. Supercrit. Fluids 2007, 41, 92-101.

(41) Porwal, J.; Karanwal, N.; Kaul, S.; Jain, S. L. Carbocatalysis: Ndoped reduced graphene oxide catalyzed esterification of fatty acids with long chain alcohols. New J. Chem. 2016, 40, 1547-1553.

(42) Yao, L.; Hammond, E.; Wang, T. Melting Points and Viscosities of Fatty Acid Esters that are Potential Targets for Engineered Oilseed. J. Am. Oil Chem. Soc. 2008, 85, 77-82.

(43) Vaver, V. A.; Ushakov, A. N.; Sitnikova, M. L.; Kolesova, N. P.; Bergel'son, L. D. Diol Lipids Communication 17. Simultaneous Gas ChromaTograPhic Determination of Diesters Of Diols And Triglycerides. Patent UDC 1972, 543.544.25:547.42.

(44) Narine, S. S.; Floros, M-C. Latent Heat Storage Using Renewable Phase Change Materials US Patent 2016, 20160214921 A1

(45) Iwasaki, T.; Maegawa, Y.; Hayashi, Y.; Ohshima, T.; Mashima, K. Transesterification of Various Methyl Esters Under Mild Conditions Catalyzed by Tetranuclear Zinc Cluster. J. Org. Chem. 2008, 73, 5147-5150.

(46) Mantri, K.; Komura, K.; Sugi, Y. Efficient Esterification of Long Chain Aliphatic Carboxylic Acids with Alcohols over $\mathrm{ZrOCl} \cdot 8 \mathrm{H}_{2} \mathrm{O}$ Catalyst. Synthesis 2005, 2005, 1939-1944. 